\title{
Stress at Work and the Role of Physical Activity in Its Management and Reduction
}

\author{
Prof. As. Dr. Zenel Orhani \\ Department of Pedagogy and Psychology, \\ University of Tirana \\ Dr. Marsela Shehu \\ Department of Social Sciences and Education, \\ Sports University of Tirana
}

Doi: 10.1515/ajis-2017-0003

\begin{abstract}
Work related stress is thought to affect an individual's psychological and physical health in different ways. The aim of the study is to identify the level of stress at work and the impact that the involvement in Physical Activity has for the overall psychological well-being and healthy lifestyle. The sample of the study includes 416 subjects aged 25 - 64 years old, 177 males and 239 females from different professions in Tirana. Instruments used are "Workplace Stress Survey" by The American Institute of Stress (AIS) and "Employee Physical Activity Survey" by EDB Sonoma County, California. The second questionnaire was modified and adapted by the authors for the purposes of this study. For statistical data processing and qualitative descriptions SPPS statistical software package, version 20, Microsoft Office Excel 2007 has been used. The data show that subjects are at a moderate level of stress at work $(60.1 \%)$, thus stress is present. The dominant gender with work stress is represented by females (60.8\%). Referring to the type of profession favoring PA, subjects claim that they cannot be involved in PA in the workplace (78.1\%). The subjects are characterized by a low level of PA performance even in their free time; on average they spend $1-2$ hours/week for $1-2$ days. As a conclusion, we can say that involvement in PA for managing and reducing stress in the workplace and not only, it is considered as one of the most important factors, it mainly focuses on reducing anxiety and irritability, and increased concentration in individuals' professional tasks.
\end{abstract}

Keywords: stress, workplace, physical activity, management, reduction.

\section{Introduction}

Stress is often described as a feeling of being overloaded, wound-up tight, tense and worried. We all experience stress at times. It can sometimes help to motivate us to get a task finished, or perform well. But stress can also be harmful if we become over-stressed and it interferes with our ability to get on with our normal life for too long. The signs of stress are such as depression, fatigue, headaches or other pains, insomnia, anxiety, anger, difficulty concentrating, low self-esteem, heart disease etc. (Australian Psychological Society, 2012).

Work related stress is the response people may have when presented with work demands and pressures that are not matched to their knowledge and abilities and which challenge their ability to cope. Poor work organization that is the way we design job and work systems and the way we manage them, can cause work stress. Excessive and otherwise unmanageable demands and pressures can be caused by poor work design, poor management and unsatisfactory working 
conditions. These things can results in workers not receiving sufficient support from others or not having enough control over their work and its pressures. When under stress, people find it difficult to maintain a healthy balance between work and nonwork life and at the same time, they may engage in unhealthy activities, such as smoking, drinking and abusing drugs. The prevention of work stress can be reducing through ergonomics, work design, organizational and management development, worker training, to developing more sensitive and responsive management systems and enhanced occupational health provision. (Leka, S. etc. al., 2003).

American Psychological Association (APA) recommend that one of the ways to reduce stress at work and not only is relaxing through techniques such as meditation, deep breathing exercises and mindfulness (a state in which you actively observe present experiences and thoughts without judging them) can help melt away stress. APPA recommend to start by taking a few minutes each day to focus on a simple activity like breathing, walking or eating a healthier diet. (www.apa.org)

In this point of view, the role of Physical Activity is very important and in particular the involvement in Physical Activity on a daily basis. For this reason, various scientific reports recommend that, for one week, adults should engage with Physical Activity for 150 minutes at its moderate level. More specifically, according to Physical Activity Guidelines for Americans (2008), although some health benefits seem to begin with as little as 60 minutes (1 hour) a week, research shows that a total amount of 150 minutes ( 2 hours and 30 minutes) a week of moderate-intensity aerobic activity, such as brisk walking, consistently reduces the risk of many chronic diseases and other adverse health outcomes. Consequently, physically active adults have a lower risk of depression and cognitive decline (declines with aging in thinking, learning, and judgment skills. Thus, as recommended, adults should strongly consider walking as a good way to get aerobic physical activity, because walking has health benefits and a low risk of injury. (U.S. Department of Health and Human Services, 2008).

\section{Methodology}

\subsection{The Sample}

The sample of the study includes 416 subjects aged 25 - 64 years old, 177 Males and 239 Females from different professions and also different workplaces such as professors or academic staff, bank workers, public administration, police officers, health workers, private sector, artists, journalist and other professions like sellers, hairdressers with different social status from single to married, divorced and widowed, with residence in the city of Tirana.

\subsection{Research Methods}

Instruments used are "Workplace Stress Survey" by The American Institute of Stress (AIS) and "Employee Physical Activity Survey" by EDB Sonoma County, California. The second questionnaire was modified and adapted by the authors for the purposes of the study and it contains 12 items. The first questionnaire measures stress level at the workplace according to Likert scale, by categories 1 - 4 Strongly Disagree, 5 - 7 Agree Somewhat and 8 - 10 Strongly Agree. Stress level measurement is performed by collecting points and their amount represents 3 levels of stress as normal, moderate and high level. The second represents a general level of physical activity at the workplace, if the types of profession favor an optimal level of physical activity and consist of open, closed and categorical questions.

\subsection{Data Analysis}

For statistical data processing and qualitative descriptions SPPS statistical software package, version 20, Microsoft Office Excel 2007 has been used. The questionnaires were administered by the authors and in completing this questionnaire the subjects' anonymity was entirely maintained. 


\section{Results and Discussion}

Stress in workplaces is one of the most influential factors that cause the individual not only a state of tension or loss of attention and concentration, but also causes many pathological diseases. According to AIS, high levels of stress at work cause physiological symptoms such as headache, fatigue, but also psychological symptoms such as anger or being irritable, etc. https://www.stress.org/

Our study data show that subjects are at a moderate level of stress at work $(60.1 \%)$ and only $11.3 \%$ of them represent a high level of stress at work. This finding of our study approves the fact that even in our country stress is present at workplaces, despite its moderate level. (Graph No. 1).

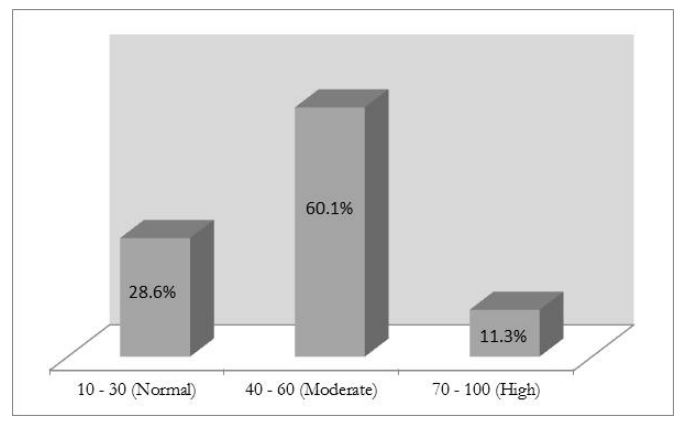

Graph No. 1: The level of stress at work in total subjects.

According to Health Advocate, Inc. job stress affects both men and women, although there are some gender differences in certain aspects. In general, women are more likely than men to experience physical symptoms of stress, such as fatigue, irritability, headaches and depression. (Health Advocate Company, 2009).

It is important that also in our study the dominant gender of stress at workplace is female, respectively at the normal level of stress at work $55.5 \%$ of them and at a moderate level $60.8 \%$ of them, meanwhile male at high levels of stress at work represent a higher percentage than women (55.3\%). (Table No. 1$)$.

Table No. 1: The level of stress at work by gender

\begin{tabular}{|l|l|c|c|c|c|}
\hline \multicolumn{2}{|l|}{ The level of stress at work } & Frequency & Percent & Valid Percent & Cumulative Percent \\
\hline $\mathbf{1 0 - 3 0}$ & Female & 66 & 55.5 & 55.5 & 55.5 \\
(Normal) & Male & 53 & 44.5 & 44.5 & 100.0 \\
& Total & 119 & 100.0 & 100.0 & \\
$\mathbf{4 0 - 6 0}$ & Female & 152 & 60.8 & $\mathbf{6 0 . 8}$ & 60.8 \\
(Moderate) & Male & 98 & 39.2 & 39.2 & 100.0 \\
& Total & 250 & 100.0 & 100.0 & \\
$\mathbf{7 0 - 1 0 0}$ & Female & 21 & 44.7 & 44.7 & 44.7 \\
(High) & Male & 26 & 55.3 & 55.3 & 100.0 \\
& Total & 47 & 100.0 & 100.0 & \\
\hline
\end{tabular}

Relationships between work stress level and demographic data, such as gender, age groups, civil status and workplaces, with the Pearson coefficient, where $r=0$, obtained through the correlation analysis, shows that there is no significance. A small significance of this relationship is observed between the civil status and the age group $r=0.494$ at level $0.01 \mathrm{Sig}$. 2 -tailed, where there is a positive correlation between these variables, as well as the negative correlation between the civil status, age and workplaces ( $r=-0.151, r=-0.140$ at level 0.01 , Sig. 2 -tailed). While between the age and gender, correlation is important at level 0.05, Sig. 2 -tailed, where $r=0.109$ (Table No. 2) 
Table No. 2: Correlations between work stress level and status, age, gender and workplaces.

\begin{tabular}{|c|c|c|c|c|c|c|}
\hline & & $\begin{array}{l}\text { The level of } \\
\text { stress at work }\end{array}$ & $\begin{array}{c}\text { Relationship } \\
\text { status }\end{array}$ & Age & Gender & Workplaces \\
\hline \multirow{3}{*}{ Work stress level } & Pearson Correlation & 1 & .086 & .070 & .029 & .048 \\
\hline & Sig. (2-tailed) & 416 & $\begin{array}{l}.080 \\
416\end{array}$ & $\begin{array}{l}.151 \\
416\end{array}$ & $\begin{array}{l}.554 \\
416\end{array}$ & $\begin{array}{l}.332 \\
416\end{array}$ \\
\hline & Pearson Correlation & .086 & 1 & $.494^{* *}$ & .038 & $-.151^{* *}$ \\
\hline \multirow[t]{3}{*}{ Relationship status } & Sig. (2-tailed) & .080 & & .000 & .440 & .002 \\
\hline & & 416 & 416 & 416 & 416 & 416 \\
\hline & Pearson Correlation & .070 & .494 & 1 & .109 & -.140 \\
\hline \multirow[t]{3}{*}{ Age } & Sig. (2-tailed) & 151 & .000 & & .026 & .004 \\
\hline & $\mathrm{N}$ & 416 & 416 & 416 & 416 & 416 \\
\hline & Pearson Correlation & .029 & .038 & $109^{*}$ & 1 & -.038 \\
\hline \multirow[t]{3}{*}{ Gender } & Sig. (2-tailed) & .554 & .440 & .026 & & .443 \\
\hline & & 416 & 416 & 416 & 416 & 416 \\
\hline & Pearson Correlation & .048 & $-.151^{* *}$ & -.140 & -.038 & 1 \\
\hline \multirow[t]{2}{*}{ Workplace } & Sig. (2-tailed) & .332 & .002 & .004 & .443 & \\
\hline & $\mathrm{N}$ & 416 & 416 & 416 & 416 & 416 \\
\hline
\end{tabular}

**. Correlation is significant at the 0.01 level (2-tailed).

*. Correlation is significant at the 0.05 level (2-tailed).

Subjects affirm that on average, 1 to 2 days a week they also work at home, so besides ordinary working days, they also import their work at home $(m=1.50, S D=2.19)$, while most of the subjects day work on a regular on average 8 hours $(m=7.67, S D=2.07)$, but some of them work longer than 8 hours, with a maximum reaching up to 14 hours of work. (Table No. 3 ).

Table No. 3: The average of working hours at home and in the workplace of subjects in total

\begin{tabular}{|l|c|c|c|c|c|}
\hline & $\mathrm{N}$ & Minimum & Maximum & Mean & $\begin{array}{c}\text { Std. } \\
\text { Deviation }\end{array}$ \\
\hline $\begin{array}{l}\text { How many days a week do you work from } \\
\text { home (not in your workplace)? }\end{array}$ & 416 & .00 & 7.00 & 1.5000 & 2.19529 \\
$\begin{array}{l}\text { How many hours do you work on a regular } \\
\text { working day? }\end{array}$ & 416 & 1.00 & 14.00 & 7.6731 & 2.07076 \\
\hline
\end{tabular}

Referring to the type of profession that favors physical activity, subjects claim that they cannot be involved in Physical Activity in the workplace (78.1\%). In addition, the subjects are characterized by a low level of Physical Activity performance even in their free time, where $54.8 \%$ of them affirm that they are not involved in Physical Activity and only $45.2 \%$ of them approve that they engage in physical activity, while if we analyze in details this result the difference between those that are not engaged in PA and those who are engaged in Physical Activity is $9.6 \%$, so it is somewhat significant, but if we analyze the involvement in Physical Activity when at the workplace and during leisure time it is noticed that the subjects have a higher percentage of involvement in Physical Activity during free time (45.2\%) compared to the workplace (21.9\%). (Graph No. 2).

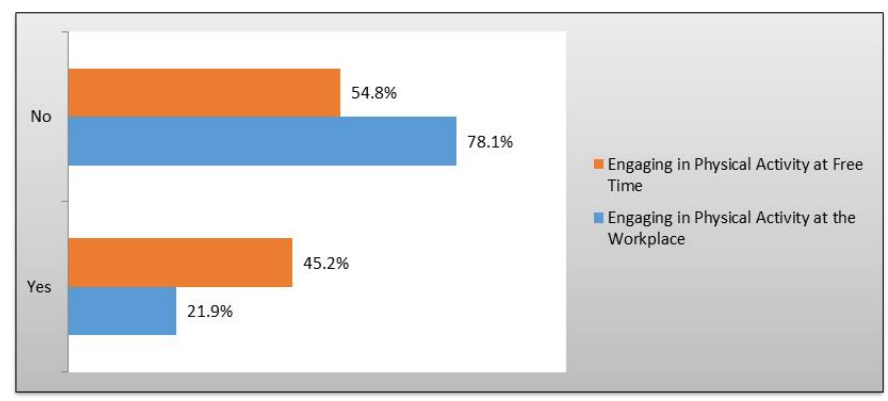

Graph No. 2: Physical Activity involvement of the subjects (in total) at their workplace and during their leisure time. 
This is also accurately confirmed by the type of activity the subjects carry out at the workplace, taking into account the percentage of time in total $100 \%$ occupied by these activities. On average subjects remain seated, they are characterized by sitting for most of the time $(m=51.14, S D=$ 30.2 ) and few of them are walking all the time. (Table No. 4).

Table No. 4: The percentage (\%) of time that the subjects spend on each of the following activities during a normal working day at their workplace.

\begin{tabular}{|c|c|c|c|c|c|}
\hline & $\mathrm{N}$ & Minimum & Maximum & Mean & Std. Deviation \\
\hline Sitting & 416 & .00 & 100.00 & 51.1418 & 30.20255 \\
Standing & 416 & .00 & 100.00 & 29.3642 & 23.10756 \\
Walking & 416 & .00 & 85.00 & 19.5445 & 17.26742 \\
\hline
\end{tabular}

This is explained by the specifics that different professions have, that they do not favor physical movement, where $27.6 \%$ of the subjects claim the fact that they totally disagree that their workplace favors Physical Activity and only $9.1 \%$ of them claim that, the workplace is conducive to engage in physical activity. (Graph No. 3).

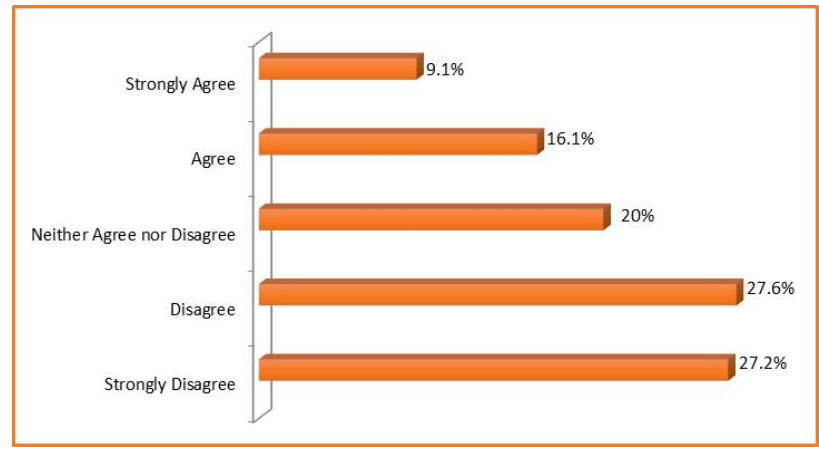

Graphic No. 3: The statements of subjects associated with the type of profession favorable to get involved in PA: "I believe that my workplace is conducive to engage in Physical Activity."

Referring to the above data, for the percentages of subjects' involvement in Physical Activity (at their workplace and during free time) presented in Graph No. 2, on average, subjects during weekdays take physical activity 1 to 2 days a week and on average 1 to 2 hours. (Table No. 5).

Table No. 5: Subjects' involvement in Physical Activity (in total) at their workplaces and during leisure time referred average of weekdays and hours dedicated to Physical Activity.

\begin{tabular}{|l|c|c|c|c|c|}
\hline & $\mathrm{N}$ & Minimum & Maximum & Mean & Std. Deviation \\
\hline Engaging in PA at the Workplace (Days) & 416 & .00 & 8.00 & .7764 & 1.83553 \\
Engaging in PA at the Workplace (Hours) & 416 & .00 & 8.00 & .5409 & 1.33110 \\
Engaging in PA at Free Time (Days) & 416 & .00 & 7.00 & 1.3365 & 1.90679 \\
Engaging in PA at Free Time (Hours) & 416 & .00 & 10.00 & 1.2260 & 1.80945 \\
\hline
\end{tabular}

One form of Physical Activity is the way we go to work, or as put differently, we say fast-moving is one of the forms that is embodied as a form of involvement with Physical Activity. If our workplace does not favor active movement or any other form that is equivalent to Physical Activity, then we can recommend that our daily needs, such as the way we go to work, or do shopping and other activities like these, should be made on foot. Data shows that our subjects (42.5\%) perform exactly this form of Physical Activity, so they walk to work and this is a very good indicator. In addition, subjects should not stay behind other sedentary forms such as travelling by car $(32 \%)$ or using 
urban transport (21.4\%). (Graph No. 4).

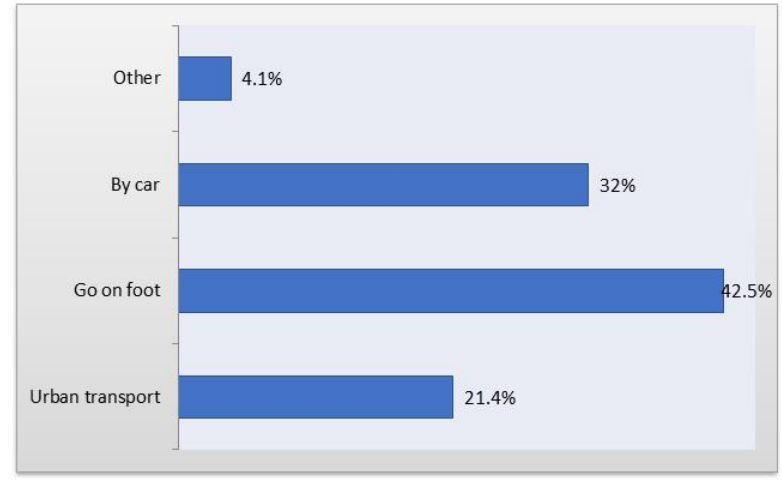

Graph No. 4: Transport modes/types and forms that the subject uses to go to work.

For substantial health benefits, adults should do at least 150 minutes ( 2 hours and 30 minutes) a week of moderate-intensity, or 75 minutes (1 hour and 15 minutes) a week of vigorous-intensity aerobic physical activity, or an equivalent combination of moderate- and vigorous-intensity aerobic activity.

From the data of our study, it turns out that only $19 \%$ of the subjects know the appropriate level of involvement with Physical Activity, appropriate level for adults for one week. According to the data, they are closer to the recognition of this level by 120 minutes $(22.1 \%)$ and 180 minutes $(21.9 \%)$, but these data are not qualitative and proper to be welcomed, even though we can say that it is a negative indicator. Each of us must be well informed about the importance of involvement in Physical Activity, above all the permissible norm that must be taken by each of us, according to the respective age groups. All of this for our health reasons, to enjoy a good psychological but also physical health. (Graph No. 5).

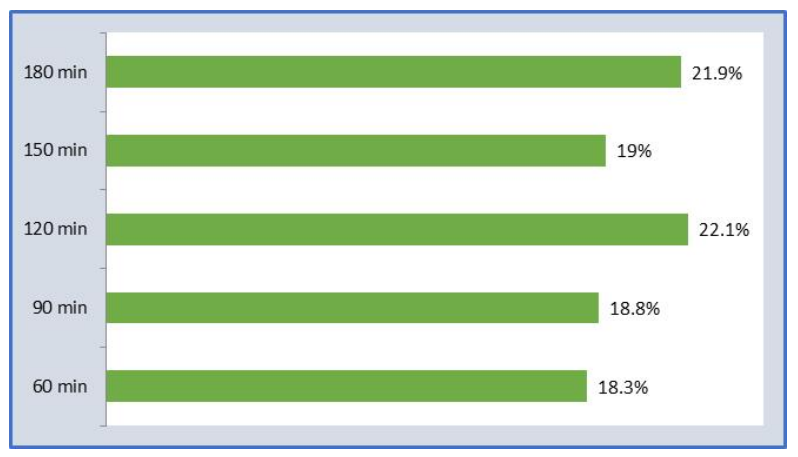

Graph No. 5: Information about the recommended level of moderate aerobic activity (i.e., fast walking) for adults for one week known by the subjects.

Subjects $(80.8 \%)$ claim that being physically active helps a lot in their performance at work, so they think that involvement in Physical Activity has a positive impact. This indicates that they know the benefits of involvement in Physical Activity and this indicator is very positive too. (Graph No. 6). 
Graph No. 6: The statements of subjects regarding the fact that being physically active has an impact on their work.

Having the advantage of being an open question and not only a categorical one, the subjects have also been able to show the concrete elements of positive influence as a result of involvement in Physical Activity. Their opinions focus mainly on psychological elements, but also on optimal physical health. Some of these opinions are:

"...It fills me up with positive energy and good humor..." (Academic Staff)

"...If I do physical activity every day, I find it easier to cope with fatigue at work..." (Police Officer)

"...I feel active and concentrated and at the same time I have less physical pain because my job is such that I sit all day long..." (Public Administration)

"...I have better artistic performance and it affects my body stability..." (Artist)

"...I feel very emotionally and physically active..." (Hairdresser)

“...It increases job concentration..." (Doctor)

"... It removes negative emotions and helps in better managing stressful situations with customers..." (Bank Worker/Cashier)

The data show that $40.1 \%$ of the subjects find it difficult to concentrate on work at $0-10 \%$ of the time, and only $2.2 \%$ at $80-100 \%$, while referring to physical discomforts $36.5 \%$ of the subjects claim that stress affects their performance at work at $0-10 \%$ of the time and only $9.6 \%$ of them affirm to have an impact at $80-100 \%$ of the time. Referring to how often it happens that worry and stress affect work performance, $31.5 \%$ of the subjects claim that they it is affected at the level of 10 $-30 \%$ of the time and only $11.1 \%$ of them represent a level of influence at $80-100 \%$ of the time. This gives the best explanation for the fact that although it does not stand at high levels, stress affects our professional performance. (Graph No. 7).

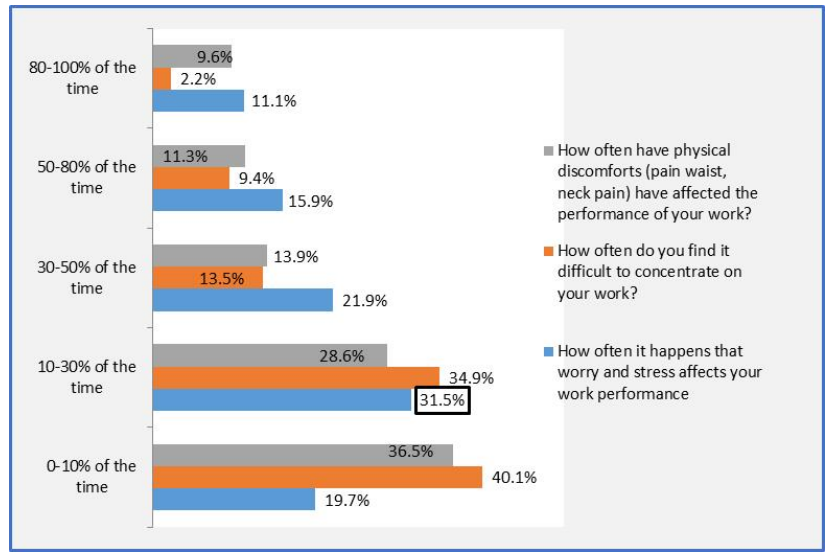

Graph No. 7: The subjects' statements with regards to the fact that stress affects physical health and well-being (at the workplaces). 


\section{Conclusion}

To conclude, we can affirm that the subjects of the study stand at the moderate level of work related stress, thus stress is present at the workplace and it mostly affects professional performance. The dominant gender affected by stress in the workplace is female, standing at a moderate level, meanwhile males stand at high levels, and therefore we may affirm exactly that job stress affects both men and women. It is also noted that there is no significant relationship between the demographic data and the level of stress in the workplace. Referring to the type of profession favoring physical activity, it is noticed that subjects are characterized by a low level of involvement in Physical Activity. Furthermore, it is noticed that the subjects have a higher percentage of involvement in Physical Activity during their free time compared to their workplaces. It is important in our study to emphasize the fact that a very small percentage of subjects know enough about the appropriate level of involvement with Physical Activity, the appropriate level for adults per one week. Most of them are informed about the benefits of involvement in Physical Activity claiming that being physically active helps a lot in their performance at work, therefore most of them have chosen to walk to work and this is a very good indicator.

\section{References}

Australian Psychological Society (2012) Understanding and Managing Stress. Available at: https://www.psychology.org.au/

Leka, S., Griffiths, A., \& Cox, T. (2003) Systematic Problem Approaches For Employers, Managers and Trade Union Representatives. Work Health Organization (WHO) Protecting Workers Health Series No. 3/3, 15 pp.

American Psychological Association (APA). Coping with stress at work. Available at http://www.apa.org /helpcenter/work-stress.aspx

U. S. Department of Health and Human Services (2008). Physical Activity Guidelines for Americans. Be Active, Healthy, and Happy! 5 - 22 pp.

The American Institute of Stress (AIS). Available at: https://www.stress.org/

Health Advocate Company (2009). Stress in the workplace meeting the challenge. Health Advocate Inc.; 7 p. 